\title{
PENDAMPINGAN PEMBELAJARAN MATEMATIKA MATERI OPERASI PERKALIAN BAGI SISWA SD KELAS II SDN 42 PALEMBANG
}

\author{
Lisnani $^{1}$, Adrianus Danang Setiawan ${ }^{2}$, Afiliani Likurnia Stevani ${ }^{3}$, Albertus Ivan Septian ${ }^{4}$ \\ 1,2,3,4Program Studi Pendidikan Guru Sekolah Dasar, Fakultas Humaniora dan Ilmu Pendidikan \\ Universitas Katolik Musi Charitas \\ Email: Lisnani@ukmc.ac.id
}

\begin{abstract}
Community service carried out by the dedication team consisted of lecturers and students of the Musi Charitas Catholic Primary School Teacher Education Study Program in cooperation with Elementary School State No.42. Community service is carried out in five meetings with a duration of two hours per meeting. Each meeting, the dedication team uses a summary of the material and questions about multiplication operations. The assistance provided by the service team outside of school hours is in the form of additional hours and is prioritized for children with low and moderate abilities. The method used is the lecture method, discussion, question and answer, and discovery learning models. In addition, this assistance process is carried out where one person accompanies a maximum of three students with the aim of getting maximum results. Output generated in this service activity is a summary of material and questions about multiplication counting operations. The summary of the material and questions provided aims to train students' abilities to more easily understand the overall multiplication operation.

Keywords: Multiplication operations, Summary of Material and Questions, Discovery Learning Model
\end{abstract}

\begin{abstract}
Abstrak. Pengabdian kepada masyarakat yang dilaksanakan oleh tim pengabdian terdiri dari dosen dan mahasiswa Program Studi Pendidikan Guru Sekolah Dasar Universitas Katolik Musi Charitas bekerjasama dengan SD Negeri 42 Palembang. Pengabdian kepada masyarakat yang dilakukan sebanyak 5 kali pertemuan dengan durasi 2 jam tiap pertemuan. Tiap pertemuan, tim pengabdian menggunakan ringkasan materi dan soal tentang operasi perkalian. Pendampingan yang dilakukan oleh tim pengabdian di luar jam sekolah berupa jam tambahan dan diutamakan bagi anak-anak yang berkemampuan rendah dan sedang. Metode yang digunakan ada metode ceramah, diskusi, tanya jawab, dan model pembelajaran discovery. Di samping itu, di dalam proses pendampingan ini dilakukan dimana 1 orang mendampingi maksimal 3 siswa dengan tujuan untuk mendapatkan hasil yang maksimal. Luaran yang dihasilkan dalam kegiatan pengabdian ini berupa ringkasan materi dan soal tentang operasi hitung perkalian. Ringkasan materi dan soal yang diberikan bertujuan untuk melatih kemampuan siswa agar lebih mudah memahami operasi perkalian secara keseluruhan.
\end{abstract}

Kata kunci : Operasi Hitung Perkalian, Ringkasan Materi dan Soal, Model Pembelajaran Discovery

\section{PENDAHULUAN}

Matematika dapat didefinisikan sebagai studi tentang struktur-struktur abstrak dengan berbagai hubungannya (Sundayana, 2014:3). Matematika adalah disiplin berpikir yang didasarkan pada berpikir logis, konsisten, inovatif, dan kreatif terhadap bilangan yang sifatnya abstrak. Matematika berfungsi mengembangkan kemampuan menghitung, mengukur, menurunkan, dan menggunakan rumus matematika yang diperlukan dalam kehidupan sehari-hari (Yuntawati dan Lalu, 2016: 13).

Di dalam matematika, terdapat materi operasi hitung dasar yang terdiri dari empat operasi hitung dasar yaitu: (1) Penjumlahan, yaitu operasi hitung untuk memperoleh dua bilangan bulat atau lebih; (2) Pengurangan, yaitu operasi hitung untuk memperoleh selisih dari dua bilangan atau lebih; (3) Perkalian, yaitu penjumlahan berulang dengan penjumlahan tetap; dan (4) Pembagian, yaitu pengurangan berulang dengan pengurangan tetap, selanjutnya bentuk operasi kali yang berulang adalah operasi pangkat.

Hingga saat ini banyak peserta didik mengalami kesulitan dalam menerima pelajaran perkalian dan pembagian. Mereka tidak hafal perkalian dasar (perkalian dua bilangan satu angka) akibatnya pelajaran matematika berikutnya akan terasa menjadi semakin sulit dan akhirnya ditakuti dan dibenci. Padahal materi perkalian di SD mulai diajarkan di kelas II semester 2 . 
Perkalian merupakan topik yang amat krusial/penting dalam pembelajaran matematika karena sering dijumpai terapannya dalam kehidupan sehari-hari (Raharjo, dkk. 2009: 1). Perkalian merupakan salah satu materi yang penting dalam pembelajaran matematika. Berdasarkan penelitian yang dilakukan oleh Prahmana dan Suwasti (2014) menyebutkan bahwa "siswa memiliki kesulitan untuk memahami konsep operasi bilangan, terutama untuk perkalian dan pembagian”. Kesalahan dalam memahami konsep matematika dikarenakan pengajar menggunakan metode yang kurang tepat, sehingga siswa kurang memahami konsep operasi bilangan (Lasena, 2014).

Di kelas rendah sekolah dasar pembelajaran perkalian bilangan cacah dipilah menjadi dua tahap, yaitu perkalian dasar (perkalian satu digit) dan perkalian lanjut (perkalian multi digit).Ketika anak belajar perkalian baik perkalian dasar maupun perkalian lanjut, mereka mengikuti suatu pola tingkatan alamiah, yakni belajar kemampuan-kemampuan dan ide-ide konsep perkalian dengan cara mereka sendiri. Setiap anak memiliki alur yang berbeda untuk sampai pada konsep perkalian bilangan cacah, baik dalam perkalian dasar maupun perkalian lanjut (Mutaqin, 2017:21).

Umumnya operasi hitung perkalian dipelajari setelah konsep penjumlahan bilangan asli dikuasai anak dengan mantap, kemudian dilanjutkan dengan penanaman konsep pengurangan. Karena sifat pengurangan yang berkebalikan dengan operasi penjumlahan, maka syarat penguasaan operasi penjumlahan menjadi mutlak untuk anak. Sebaiknya anakanak yang belum menguasai penjumlahan dengan mantap, perlu mendapat perhatian khusus dari guru baik dengan cara pembimbingan secara individual maupun meminta bantuan orang tua.

Perkalian sebagai penjumlahan berganda, memerlukan tahap berpikir yang lebih kompleks pada diri anak. Oleh karena itu jika anak tampak belum siap memulai materi perkalian sebaiknya diingatkan kembali tentang operasi penjumlahan. Setelah operasi perkalian dapat dikuasai dengan baik, selanjutnya adalah operasi pembagian. Menurut Wahyudin \& Sudrajat (2003: 37), operasi pembagian merupakan kebalikan dari operasi perkalian. Oleh karena itu penguasaan operasi perkalian menjadi mutlak agar dapat menguasai operasi pembagian

SD Negeri 42 Palembang merupakan SD Negeri yang terletak di Kecamatan Ilir Timur 1 Palembang. SD Negeri 42 merupakan SD yang terdiri dari kelas pagi yaitu kelas I, II, dan VI sedangkan kelas siang terdiri dari kelas III, IV, dan V. Kelas II terdiri dari tiga kelas yaitu IIA berjumlah 10 siswa, IIB berjumlah 22 orang, dan IIC berjumlah 19 orang. Jumlah keseluruhan siswa kelas II 63 orang terdiri dari 35 orang berjenis kelamin laki-laki dan 27 orang berjenis kelamin perempuan. Dari keseluruhan siswa kelas II, tim pengabdian hanya mengambil 15 orang siswa yang memiliki kemampuan rendah dan sedang yang terdiri dari kelas IIA berjumlah 6 orang, kelas IIB berjumlah 9 orang terutama dalam materi operasi perkalian. Alasannya agar kegiatan pendampingan yang dilakukan lebih maksimal, fokus, dan terarah.

Pada tahap awal Berdasarkan hasil wawancara dengan guru kelas III diperoleh informasi sebagai berikut: 1) bahwa ada beberapa siswa yang kurang memahami tentang operasi hitung perkalian; 2) keterbatasan waktu di dalam pembelajaran di kelas karena banyak materi; 3) jumlah siswa yang cukup banyak dalam satu kelas membuat guru mengalami kesulitan untuk membuat siswa mengerti; 4) keterbatasan ekonomi keluarga karena sekolah ini merupakan sekolah gratis dengan bantuan dana dari pemerintah.

Padahal operasi hitung perkalian merupakan konsep dasar yang harus dikuasai siswa secara menyeluruh sejak di SD. Hal ini dikarenakan ditingkat SMP dan SMA, operasi perkalian dipelajari lebih mendalam di berbagai materi IPA. Maka dari itu, pemahaman konsep siswa tentang operasi perkalian sejak awal sangat dibutuhkan.

Berdasarkan data yang diperoleh dari guru kelasnya, ada sekitar 15 siswa yang kurang memahami tentang operasi perkalian. Maka dari itu, dosen dan mahasiswa Program Studi PGSD ingin memberikan pendampingan kepada siswa kelas II di SD Negeri 42 Palembang agar memahami tentang operasi hitung perkalian. Dosen dan mahasiswa membuat ringkasan materi 
dan soal untuk memudahkan proses pendampingan operasi hitung perkalian. Ringkasan materi dan soal berisi konsep secara sederhana hingga analisis untuk melatih kemampuan siswa.

Di awal dosen bersama mahasiswa memberikan pretest (siswa pernah mempelajari operasi hitung perkalian namun belum menguasai secara utuh dan menyeluruh). Pretest (tes awal) diberikan untuk mengetahui nilai siswa sebelum diberikan pendampingan. Setelah diberikan pendampingan oleh tim pengabdian maka siswa akan diberikan posttest (tes akhir) kembali. Tujuan pemberian posttest adalah untuk mengetahui tingkat keberhasilan pendampingan yang dilakukan oleh tim pengabdian.

Berdasarkan hal keprihatinan tersebut, dosen dan mahasiswa Program Studi PGSD ingin memberikan pendampingan matematika materi operasi perkalian kepada siswa kelas II di SD Negeri 42 Palembang.

\section{METODE PELAKSANAAN}

Kegiatan ini dilakukan dalam bentuk pendampingan pembelajaran matematika materi operasi perkalian bagi siswa kelas II di SD Negeri 42 Palembang. Setelah diberikan pendampingan diharapkan siswa dapat lebih memahami tentang materi dan soal-soal operasi perkalian. Berikut ini adalah tahapan pendampingan yang dilakukan:

a. Tahap Persiapan

Tahap persiapan dilakukan kurang lebih 3 bulan. Tahap persiapan yang dilakukan meliputi:

1) observasi awal

2) pemantapan dan penentuan lokasi dan sasaran

3) diskusi/pertemuan dengan Kepala Sekolah dan guru kelas II SD Negeri 42 Palembang

4) rapat bersama

a. sesama tim pengabdian yang terdiri dari dosen dan mahasiswa Program Studi PGSD terkait dengan bentuk pendampingan dan pelaksanaan

b. dosen dengan mahasiswa membahas tentang jadwal pelaksanaan pengabdian dan lokasi pengabdian
5) penyusunan ringkasan materi dan soal tentang operasi perkalian, soal pretest dan soal posttest (ringkasan materi dan soal tentang operasi perkalian dan jadwal pendampingan terlampir).

b. Tahap Pelaksanaan Kegiatan

Kegiatan pendampingan pembelajaran matematika materi operasi perkalian bagi siswa kelas II di SD Negeri 42 Palembang dilaksanakan selama $5 \mathrm{x}$ pertemuan dengan durasi \pm 2 jam (jadwal kegiatan terlampir). Tahap pelaksanaan kegiatan diawali dengan pemberian pretest kepada siswa yang didampingi, pendampingan menggunakan metode ceramah, penggunaan media berupa jaritmatika sederhana dan Tulang Napier untuk membuat siswa memahami operasi perkalian, pendampingan secara kelompok (1 guru maksimal 4 siswa) menggunakan ringkasan materi dan soal yang telah dipersiapkan, dan pemberian posttest.

Setelah kegiatan pendampingan selesai dilanjutkan sesi foto bersama siswa kelas II di SD Negeri 42 Palembang, dan pemberian kenang-kenangan Kepala SD Negeri 42 Palembang. Untuk melaksanakan kegiatan tersebut digunakan beberapa metode yaitu sebagai berikut:

1) Metode ceramah

$$
\begin{aligned}
& \text { Metode ceramah dipilih untuk } \\
& \text { memberikan penjelasan tentang } \\
& \text { konsep operasi perkalian }
\end{aligned}
$$

2) Metode permainan

Metode permainan bertujuan untuk mengurangi kebosanan di dalam pembelajaran melalui penggunaan jaritmatika sederhana dan tulang Napier.

3) Metode pemecahan masalah

Metode pemecahan masalah diberikan terkait dengan soal-soal pemecahan masalah yang diberikan oleh tim pengabdian. Metode ini bertujuan untuk melatih kemampuan berpikir siswa.

4) Metode diskusi

Metode ini bertujuan agar ada interaksi antara tim pengabdian (berperan sebagai guru) dengan siswa.

5) Metode tanya jawab 
Metode ini bertujuan agar ada interaksi antara tim pengabdian (berperan sebagai guru) dengan siswa.

6) Metode resitasi

Metode ini bertujuan untuk melatih pemahaman siswa terkait dengan konsep yang telah dipelajari siswa melalui pemberian tugas/latihan.

Selama kegiatan pendampingan ini berlangsung, pihak mitra yaitu SD Negeri 42
Palembang menyediakan tempat dan siswa kelas II yang akan mengikuti pendampingan. Kegiatan pengabdian dilaksanakan pada tanggal 4, 9, 10, 11, dan 20 Mei 2019 di SD Negeri 42 Palembang pada pukul 12.30 14.30 WIB dengan rincian jadwal seperti pada Tabel 1.

Tabel 1. Jadwal Pendampingan Pembelajaran Matematika Materi Tabel 1. Operasi Perkalian Bagi Siswa Kelas II di SD Negeri 42 Palembang

\begin{tabular}{ll}
\hline \multicolumn{1}{c}{ Waktu } & \multicolumn{1}{c}{ Sabtu, 4 Mei 2019 } \\
\hline Pukul 12.30-13.30 & \multicolumn{1}{c}{ Kegiatan } \\
\hline Pukul 13.30-14.30 & $\begin{array}{l}\text { Pemberian pretest (tes awal) } \\
\text { dasar dalam bentuk soal sederhana menggunakan ringkasan materi dan } \\
\text { soal }\end{array}$ \\
\hline & \multicolumn{1}{c}{ Kamis, 9 Mei 2019 } \\
\hline Pukul 12.30-14.30 & $\begin{array}{l}\text { Penggunaan jaritmatika dan tulang Napier di dalam operasi perkalian } \\
\text { Mengetes kemampuan perkalian 1 - 10 seluruh siswa yang mengikuti } \\
\text { pendampingan }\end{array}$ \\
\hline & \multicolumn{1}{c}{ Jumat, 10 Mei 2019 } \\
\hline Pukul 12.30-14.30 & $\begin{array}{l}\text { Pemberian materi dan konsep tentang operasi perkalian tingkat lanjutan } \\
\text { dalam bentuk soal sederhana menggunakan ringkasan materi dan soal }\end{array}$ \\
\hline & Sabtu, 11 Mei 2019 \\
\hline Pukul 12.30-14.30 & $\begin{array}{l}\text { Pembagian kelompok kecil untuk melakukan fokus pemahaman tiap } \\
\text { siswa secara utuh dan menyeluruh }\end{array}$ \\
\hline & \multicolumn{1}{c}{ Senin, 20 Mei 2019 } \\
\hline Pukul 12.30-13.30 & Pemberian posttest (tes akhir) \\
\hline Pukul 13.30-14.30 & $\begin{array}{l}\text { Foto bersama siswa yang ikut pendampinga } \\
\text { Pemberian kenang-kenangan kepada SD Negeri 42 Palembang }\end{array}$ \\
\hline
\end{tabular}

\section{HASIL DAN PEMBAHASAN}

Tim pengabdian kemampuan dari 15 orang siswa (dengan kriteris melaksanakan pengabdian sebanyak 5 (lima) kali tatap muka diawali dengan pretest diperoleh hasil pretest dari 15 orang siswa bervariatif dengan nilai rata-rata pada pretest sebesar 40,47. Hal ini menunjukkan
6 siswa berkemampuan sedang dan 9 siswa berkemampuan rendah) membutuhkan pendamping terkait materi operasi perkalian $\begin{array}{lll}\text { seperti } & \text { pada } & \text { Gambar }\end{array}$

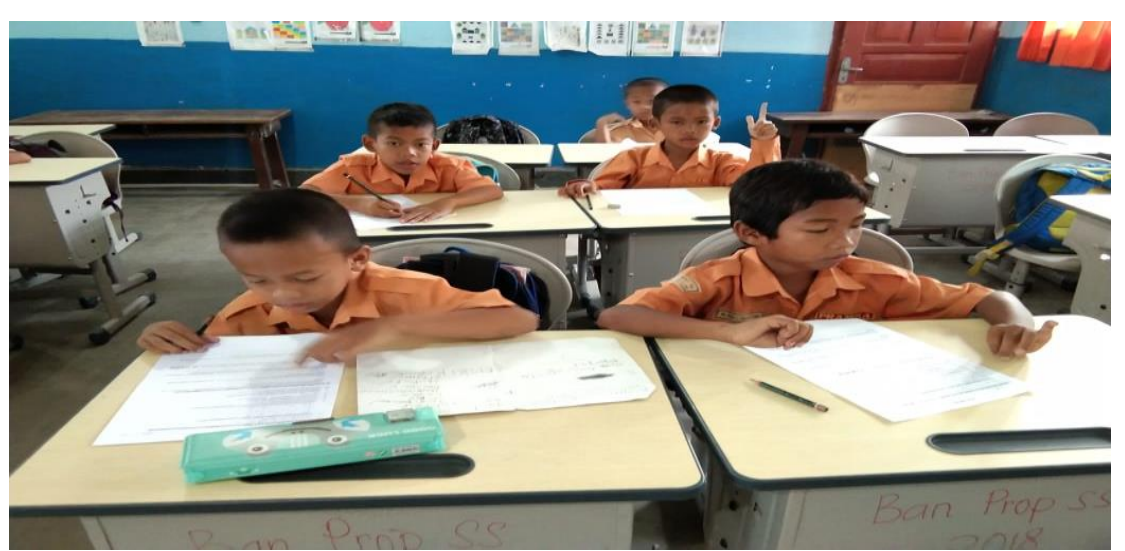

Gambar 1. Siswa mengerjakan soal pretest 
Pada tahap awal, tim pengabdian membagi peserta menjadi 4 kelompok dimana tiap kelompok didampingi oleh 1 orang pengajar (yang merupakan anggota tim pengabdian). Siswa bahkan belum sama sekali memahami perkalian 1-5 seperti pada Gambar 2 dan 3. Maka dari itu, pada tahap awal ketua tim memberikan materi operasi perkalian menggunakan konsep penjumlahan berulang seperti Gambar 4.

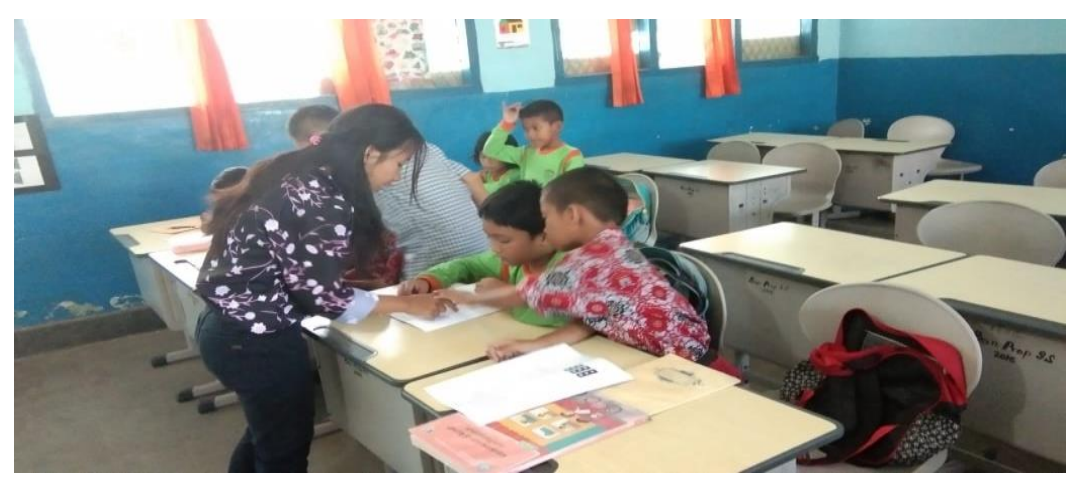

Gambar 2. Pengajaran secara kelompok didampingi oleh Afiliani Likurnia (mahasiswa)

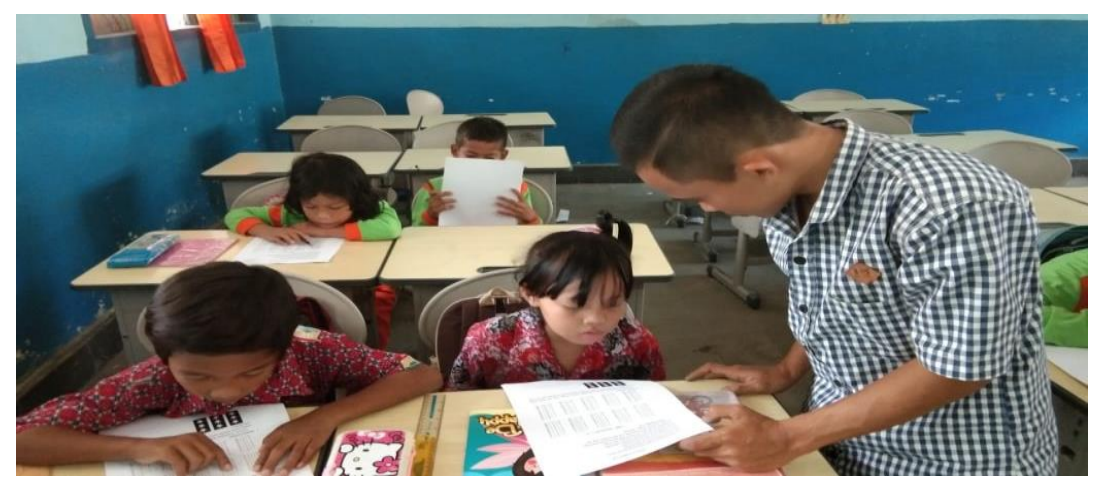

Gambar 3. Pengajaran secara kelompok didampingi oleh Albertus Ivan (mahasiswa)

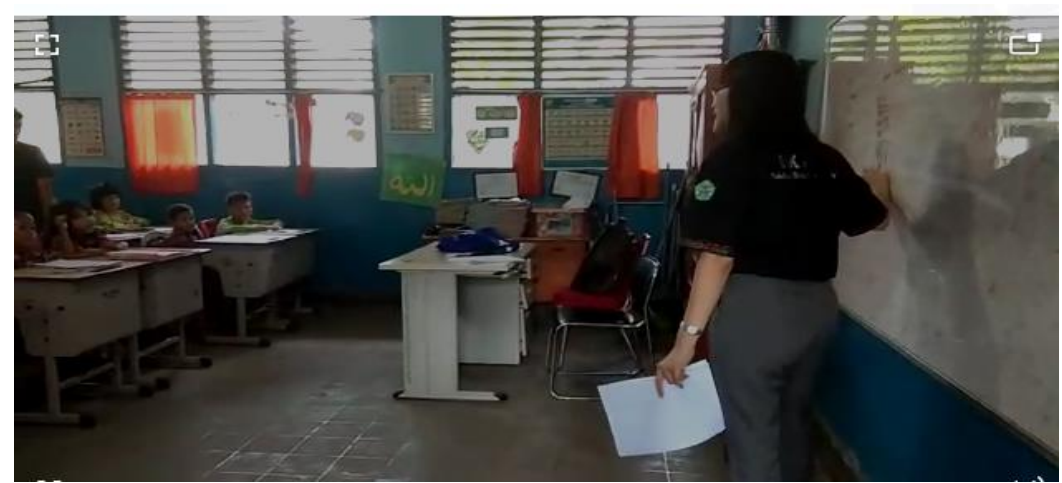

Gambar 4. Penyampaian materi oleh ketua tim pengabdian yaitu Lisnani

Teknik yang digunakan oleh tim pengabdian juga melalui permainan sederhana menggunakan konsep operasi penjumlahan berulang. Selama beberapa kali pertemuan, menunjukkan adanya peningkatan dari beberapa siswa yaitu sekitar 8 siswa sudah mulai memahami operasi perkalian. Akan tetapi karena keterbatasan waktu (hanya 5x pertemuan dan siswa pun akan mengikuti ujian akhir sekolah) maka tim pengabdian hanya terbatas pada perkalian 1-5 di tahap awal ini. Di tahap akhir, tim pengabdian melakukan posttest dan diperoleh hasil 51,67 seperti Tabel 2. 
Tabel 2. Hasil Pretest dan Posttest Siswa

\begin{tabular}{ccccc}
\hline No & Nama & Kelas & Nilai Pretest & Nilai Posttest \\
\hline 1 & VS & IIA & 50 & 60 \\
\hline 2 & MF & IIA & 53 & 70 \\
\hline 3 & M & IIA & 2 & 24 \\
\hline 4 & T & IIA & 53 & 53 \\
\hline 5 & M. AC P & IIA & 45 & 60 \\
\hline 6 & FD & IIA & 28 & 32 \\
\hline 7 & KA K & IIB & 28 & 32 \\
\hline 8 & NH & IIB & 20 & 40 \\
\hline 9 & MA & IIB & 48 & 53 \\
\hline 10 & D & IIB & 43 & 56 \\
\hline 11 & M. RR & IIB & 56 & 67 \\
\hline 12 & M. A & IIB & 48 & 88 \\
\hline 13 & M. R & IIB & 59 & 15 \\
\hline 14 & M. F & IIB & 15 & 75 \\
\hline 15 & M. RK & IIB & 59 &
\end{tabular}

Siswa mengalami peningkatan namun tidak signifikan dikarenakan keterbatasan waktu dalam pelaksanaan kegiatan pendampingan ini seperti Gambar 5.

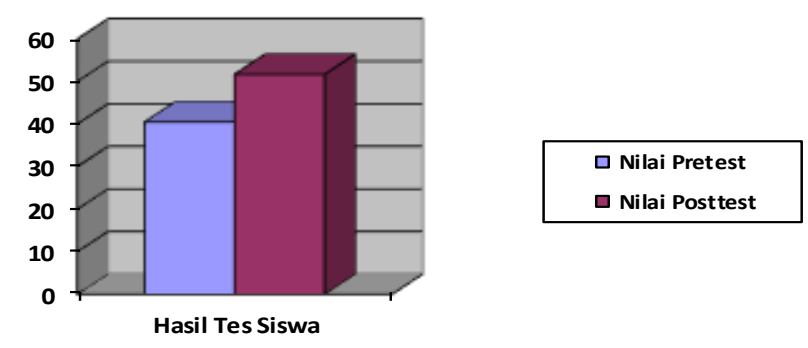

\section{Gambar 5. Hasil Pretest dan Posttest Siswa}

Di samping itu, tim pengabdian juga memberikan kuesioner/ angket kepada seluruh siswa. Kuesioner/ angket adalah alat pengumpul data yang berbentuk pertanyaan yang akan diisi atau dijawab oleh responden (Muljono dan Djaali, 2008: 64). Dari kuesioner tersebut diperoleh hasil sebagai berikut: 1) Topik kegiatan menarik: (setuju sebanyak 100\%); 2) Bahan/materi kegiatan menarik: (setuju sebesar 100\%); 3) Penyampaian materi/ bahan jelas (setuju sebesar $66,67 \%$ dan sangat setuju sebesar 33,33\%); 4) Bentuk kegiatan menarik (setuju sebesar $80 \%$ dan sangat setuju sebesar 20\%); 5) Kegiatan ini sangat bermanfaat (setuju sebesar $73,33 \%$ dan sangat setuju sebesar 26,67\%); 6) Kegiatan berikutnya dengan topik berbeda sangat diharapkan (setuju sebesar 100\%).

\section{SIMPULAN DAN SARAN}

Program kegiatan pendampingan pembelajaran matematika materi operasi perkalian bagi siswa SD Kelas II di SD Negeri 42 Palembang dirasakan bermanfaat bagi siswa agar lebih memahami tentang konsep operasi hitung perkalian. Akan tetapi, didalam pelaksanaan pengabdian ini masih terdapat keterbatasan dalam pelaksanaannya yaitu waktu yang belum maksimal karena pihak sekolah hanya memberikan durasi waktu yang terbatas di dalam pelaksanaan kegiatan pendampingannya.

Di samping itu, berdasarkan hasil kuesioner diperoleh saran/masukan dari peserta terkait perlunya kegiatan pendampingan dilakukan secara rutin, pendampingan yang diberikan tidak hanya materi tentang operasi 
hitung perkalian, dan perbanyak permainan matematika untuk mengurangi kebosanan di dalam pembelajaran.

\section{UCAPAN TERIMAKASIH}

Ucapan terimakasih disampaikan kepada: 1) pihak SD Negeri 42 Palembang yaitu kepala sekolah, guru dan siswa yang bersedia menyediakan tempat dan waktu di dalam pelaksanaan pengabdian ini, 2) mahasiswa Program Studi PGSD Universitas Katolik Musi Charitas yang ikut serta dalam kegiatan pengabdian ini.

\section{DAFTAR PUSTAKA}

Lasena, A., Ora, R. G., \& Sulistiawati. (2014). Penerapan Pembelajaran Matematika GASING Untuk Meningkatkan Kemampuan Pemahaman Matematis Siswa Kelas III Sekolah Dasar pada Perkalian. Prosiding Seminar Nasional Pendidikan Matematika Ahmad Dahlan, 27 Desember 2014. Yogyakarta.

Muljono \& Djaali, P. (2008). Pengukuran dalam Bidang Pendidikan. Jakarta: Grasindo.

Mutaqin, E.J. (2017). Analisis Learning Trajectory Matematis dalam Konsep Perkalian Bilangan Cacah di Kelas Rendah Sekolah Dasar. Dwijacendekia
Jurnal Riset, 1(1), 19-33.

Prahmana, R. C. I \& Suwasti, P. (2014). Local Instruction Theory on Division In Mathematics GASING: The Case of Rural Area's Students In Indonesia. Journal of Mathematics Educations, 5(01), 391-398.

Raharjo, M,. Astuti W., \& Titik, S. (2009). Modul Matematika SD Program BERMUTU: Pembelajaran Operasi Hitung Perkalian dan Pembagian Bilangan Cacah di SD. Yogyakarta: P4TK Matematika.

Sundayana, R. (2014). Media dan Alat Peraga dalam Pembelajaran Matematika. Bandung: Alfabeta.

Taufina. (2017). Buku Tematik Terpadu Kurikulum 2013 Tema 5: Pengalamanku. Jakarta: Kementerian Pendidikan dan Kebudayaan.

Wahyudin \& Sudrajat, (2003). Ensiklopedi Matematika dan Peradaban Manusia. Jakarta: Tarity Samudra Berlian.

Yuntawati \& Lalu, A.A., (2016). Pengembangan Media Congklak pada Pengembangan Media Congklak pada Mata Pelajaran Matematika Materi Pokok Operasi Hitung Perkalian dan Pembagian Kelas III SDN 7 Pemenang Barat. Jurnal Ilmiah IKIP Mataram, 4(1), 12-17. 